\title{
ДИПЛОМАТИЯ
}

Калачев Д.Н.

DOI: 10.7256/2305-560X.2015.1.13711

\section{ПРОБЛЕМЫ АДАПТАЦИИ ДОГОВОРА ОБ ОБЫЧНЫХ ВООРУЖЕННЫХ СИЛАХ В ЕВРОПЕ}

\begin{abstract}
Аннотация: Статья анализирует одну из ключевых проблем взаимоотношения России и НАТО - проблему адаптации Договора об обычных вооруженных силах в Европе (ДОВСЕ). Статья кратко останавливается на предыстории и истории появления ДОВСЕ, анализирует причины его кризиса и возникновения потребности в адаптации договора к современным геополитическим условиям. Изучая дисбалансы соотношения вооруженных сил НАТО и России в Европе и примеры наступательной политики США и НАТО вблизи границ России, автор показывает причины приостановления действия Договора со стороны России и говорит о перспективах возобновления сотрудничества между Россией и НАТО по данному вопросу. Методологическую основу исследования составляют системный, структурно-функциональный, сравнительно-исторический, сравнительно-политический, геополитический и культурно-цивилизационный подходы, методы анализа, синтеза, индукции, дедукции, моделирования, наблюдения. В настоящей статье автором делается вывод о том, что преодоление кризиса взаимоотношений между странами НАТО и России является вполне реальной перспективой, но оно должно осуществляться лишь на равноправной основе и в рамках международного права на основе юридически закрепленных межгосударственных договоренностей.
\end{abstract}

Ключевые слова: международные отношения, внешняя политика, международный конфликт, ДОБСЕ, Россия, НАТО, интересы, ценности, безопасность, дипломатия.

0 тношения России и НАТО за свою более чем двадцатилетнюю историю испытывали как «взлеты», выражавшиеся в закреплении и институционализации сотрудничества (с кульминацией в мае 2002 г. в виде создания Совета Россия-НАТО), так и «падения» по причине различных международных кризисов и конфликтов (косовский кризис, грузино-югоосетинский конфликт и присоединение Крыма к России в 2014 г.), но то, что оставалось неизменным - это элемент скрытого или явного соперничества между сторонами ${ }^{1}$.

Взаимодействуя по обширному списку вопросов безопасности, Россия и НАТО неизбежно вынуждены взаимодействовать по некоторым острым проблемным вопросам, имеющим непосредственное отношение к национальной безопасности России. Среди таких вопросов можно назвать проблему расширения НАТО, проблему адаптации Договора об обычных вооруженных силах в Европе, проблему размещения системы ПРО США в Европе и вопрос о статусе различных территорий (Косово, Абхазия, Южная Осетия и Крым). В данной статье мы рассмотрим проблему адаптации ДОВСЕ.

\footnotetext{
1 Противоречия России и НАТО // inoСМИ [сайт]. - 2014 г.
} - 07 янв.: URL: http://inosmi.ru/world/20140107/216322215.html
В период холодной войны сложилась существенная асимметрия противостоящих военных блоков. Так, по боевым танкам и артиллерии Организация Варшавского договора превосходила силы НАТО более чем в два раза. Важно заметить, что ограничения обычных вооружений в этот период активно добивались государства Западной Европы, видевшие в СССР угрозу своей безопасности.

После длительных переговоров и определенных уступок, преимущественно со стороны Советского Союза, шестнадцатью странами-членами НАТО и шестью странами-участницами Варшавского договора 19 ноября 1990 года в Париже (Франция) был подписан юридически обязательный бессрочный «Договор об обычных вооруженных силах в Европе» - ДОВСЕ. Как указывает один из наиболее известных академических специалистов в области международных отношений - А.И. Уткин: «Москва пошла на феноменальные сокращения своих обычных вооруженных сил в Европе, полагаясь на обещание Запада, данное в Парижской хартии ноября 1990 года «О безблоковой Европе»².

\footnotetext{
2 Уткин А.И. Американская империя. - М,: Эксмо, 2003. C. 488
} 
ДОВСЕ вступил в силу в ноябре 1992 года и определял количественные ограничения на развертывание пяти наиболее дестабилизирующих категорий обычных вооруженных сил в Европе ${ }^{3}$ : боевых танков, боевых бронированных машин (ББМ), артиллерии, боевых самолетов и вертолетов, - по тем видам вооружения, по которым Варшавский блок превосходил НАТО. Принятый документ позволял на основе взаимной открытости в военной сфере провести быстрое и сбалансированное сокращение большого количества избыточных тяжелых вооружений и выйти на их равные предельные уровни для НАТО и ОВД. Кроме того, в тексте документа прямо утверждалось, что «настоящий Договор не имеет целью оказать отрицательное воздействие на интересы безопасности любого государства». Ограничения ДОВСЕ не распространялись на военно-морские силы, стратегическую авиацию и географию базирования тактической и армейской авиации. Не учитывалось ядерное оружие, не принимались в расчет новые формы (воздушные и воздушно-космические операции, операции стратегических ядерных сил и др.) и, тем более, новые способы ведения стратегических операций, новые технологии управления конфликтами ${ }^{5}$. ДОВСЕ, по существу, был разработан таким образом, что его положения никак не влияли на наступательные и оборонительные возможности США - основного участника НАТО и его главную военную силу. Процесс сокращения обычных вооружений был призван к укреплению взаимного доверия и стабильности на европейском континенте, а сам договор признан «краеугольным камнем европейской безопасности» ${ }^{6}$.

Однако кардинально изменившаяся военнополитическая ситуация в Европе: прекращение существования СССР и Варшавского договора, расширение НАТО, в том числе и за счет бывших со-

\footnotetext{
3 Район применения Договора включил в себя всю сухопутную часть государств-участников в Европе от Атлантического океана до Уральских гор: все европейские островные территории, территорию к западу от реки Урал и Каспийского моря и территорию турецкой Республики к северу и западу от линии пересечения турецкой границы с 39-й параллелью. См. Договор об обычных вооруженных силах в Европе. Париж, 19 ноября 1990 года.

4 Договор об обычных вооруженных силах в Европе. Париж, 19 ноября 1990 года.

5 Манойло А.В. Национально-государственные модели психологического управления конфликтами. // Обозреватель-Observer. -2008. - №2. - С.118-123.

6 См. напр. текст Римской декларации 2002 г.
}

ветских республик, и как следствие - образование близ российских границ новых государств, которые не являлись участниками ДОВСЕ, что подрывало баланс прав и обязательств сторон, - потребовала адаптации Договора к новым условиям. Кроме того, российская сторона неоднократно высказывала возражения в связи с установленными ДОВСЕ так называемыми фланговыми ограничениями, подразумевающими необходимость поддержания Российской Федерации довольно низкого уровня вооружений и военной техники в своих приграничных регионах: в Ленинградском (ЛВО) и Северо-Кавказском (СКВО) военных округах. Ввиду возрастания угроз национальной безопасности, исходящих от международного терроризма и дестабилизации обстановки на южных границах страны, данные ограничения были неприемлемы для Российской Федерации.

В принятом Россией и НАТО Основополагающем акте 1997 года признается важность адаптации ДОВСЕ для работы над моделью «...бщей и всеобъемлющей безопасности для Европы XXI века...» ${ }^{7}$ и утверждается, что общей целью государств-участников ОБСЕ является «...заключение соглашения об адаптации в возможно более сжатые сроки...».

Соглашение об адаптации Договора об обычных вооруженных силах в Европе было подписано в ноябре 1999 года на Стамбульском саммите Организации по Безопасности и Сотрудничеству в Европе, в котором закреплялась трансформация из системы блоковых ограничений к установлению для каждого государства предельных национальных и территориальных уровней вооружений. Вместо пяти географических зон, на которые прежде был разбит район применения Договора, вводилась сеть территориальных ограничений: 28 территориальных уровней в соответствии с числом европейских участников договора, а также два подуровня - на территории России и Украины. Были определены национальные и территориальные квоты по некоторым видам обычных вооружений, больше учитывающие интересы Россиия.

Адаптированный ДОВСЕ предусматривает существенное сокращение национальных уровней вооружений в 19 государствах-членах НАТО (на

\footnotetext{
7 Раздел IV. Основополагающего акта 1997 г.

8 Раздел IV. Основополагающего акта 1997 г.

9 Арешев А.Г. ДОВСЕ. Устаревший договор и новые реалии // Международная жизнь. - 2007. - № 12. С. 128
} 
тот момент) по сравнению с предыдущими параметрами: по танкам - более чем на 4800 ед., по ББМ - на 4000 ед., по артиллерии - более чем на 4000 ед., что соответствует вооружению примерно десяти отмобилизованных дивизий натовского стандарта $^{10}$. Напротив, для Российской Федерации эти параметры сохранились неизменными: 6350 ед. танков, 11280 ед. боевой бронированной техники, 6315 ед. артиллерийских систем, 3416 боевых самолетов, 855 ед. ударных вертолетов. Вместе с тем, Россия получила возможность иметь в регулярных частях новой фланговой зоны (ЛВО без Псковской области и СКВО - без Волгоградской, Астраханской областей и восточной части Ростовской) в четыре раза больше ББМ: 2140 вместо 580 ед., а также временно развертывать здесь дополнительно 153 танка и 140 ед. артиллерии.

Таким образом, принятие данного Соглашения могло послужить решению многих и важных для укрепления европейской безопасности военно-политические задач. Однако большинство из 30 стран $^{11}$ (за исключением Белоруссии, Казахстана, России и Украины), подписавших Соглашение об адаптации и Заключительный акт конференции государств-участников ДОВСЕ, отказалось от их ратификации.

Несмотря на утверждения о равноправном сотрудничестве в рамках СРН «с целью ратификации всеми государствами-участниками Соглашения об адаптации ДОВСЕ и его вступлении в силу» ${ }^{12}$, НАТО по-прежнему руководствуется отражающим реалии конца холодной войны и безнадежно устаревшим, но устраивающим его блоковым вариантом Договора, который уже не ограничивает военный потенциал Альянса, но ставит в крайне невыгодное положение Россию. Так, на 1 января 2006 года вооруженные силы стран НАТО превосходили российские по танкам в 2,9 раза, ББМ и артиллерийским системам - в 2,8 раза, боевым самолетам - в 4,1 раза $^{13}$.

Попытки соотнести положения Договора в соответствии с меняющейся военно-политической обстановкой в европейском регионе предприни-

\footnotetext{
10 Пояснительная записка по вопросу о ратификации Соглашения об адаптации Договора об обычных вооруженных силах в Европе. См. http://asozd.duma.gov.ru

11 Кулагин В.М. Международная безопасность: учебное пособие для студентов вузов. - М.: Аспект Пресс, 2007. С. 181

12 Римская декларация 2002 г.

13 Евсеев В. Обычные вооружения: Россия и Запад в зеркале ДОВСЕ // ВЕДОМОСТИ. - 2007. - 12 дек. - № 235 (2009).
}

мались Российской Федерацией в рамках СРН на протяжении ряда лет. В ответ на претензии России партнеры по Совету с завидной настойчивостью заявляли, что ратификация адаптированного ДоВСЕ зависит от выполнения Российской Федерацией «стамбульских обязательств», под которыми понимается широкий спектр ничем не обоснованных требований к российской стороне. При этом все признают, что Российская Федерация в полной мере выполнила все обязательства, предусмотренные положениями как ДОВСЕ, так и Соглашения о его адаптации.

26 апреля 2007 года в г. Осло (Норвегия) состоялось заседание СРН, где наряду с обсуждением вопросов практического сотрудничества: противодействия наркотрафику из Афганистана, ПРО ТДВ в рамках операции «Активные усилия» и программой работы на 2007 г., продолжились дискуссии по поводу размещения объектов ПРО США в Европе и по проблеме адаптации ДОВСЕ. Выступивший по итогам заседания Министр иностранных дел Российской Федерации С.В. Лавров отметил положительную динамику развития пятилетнего сотрудничества в сфере европейской безопасности в рамках Совета, но указал на недостаточность использования потенциала созданной структуры и нехватку доверия. Утром того же дня Президент Российской Федерации В.В. Путин объявил о введении моратория на исполнение Россией ДОВСЕ и предложил обсудить эту проблему в Совете Россия-НАТО: если прогресса не будет, то необходимо прекратить выполнение обязательств по этому договору. Члены НАТО «выразили обеспокоенность» в связи с объявлением, но не предприняли встречных шагов.

13 июля 2007 года Президент России В.В. Путин подписал Указ «О приостановлении Российской Федерацией действия Договора об обычных вооруженных силах в Европе (ДОВСЕ) и связанных с ним международных договоров», приостановившего участие России в данном договоре, начиная с 12 декабря 2007 года ${ }^{14}$. Официально было заявлено, что такая мера принимается в связи со следующими исключительными обстоятельствами, затрагивающими национальную безопасность РФ:

\footnotetext{
14 П.2 ст. ХІХ Договора гласит: «Каждое государство-участник в порядке осуществления своего национального суверенитета имеет право выйти из настоящего Договора, если оно решит, что относящиеся к содержанию настоящего договора исключительные обстоятельства поставили под угрозу его высшие интересы».
} 
Дипломатия / Diplomacy

- превышение групповых ограничений Договора в результате значительного расширения состава стран-участников НАТО;

- предполагаемое размещение на территории Болгарии и Румынии американских военных баз;

- невыполнение западными странами-участниками ДОВСЕ обязательств по ускоренной ратификации Соглашения об адаптации договора, принятых в ноябре 1999 года на стамбульском саммите ОБСЕ.

Важно понимать, что приостановление действия договора не означает окончательного выхода из него. Как указано в справке к Указу, мораторий продлится до тех пор, «пока страны НАТО не ратифицируют Соглашение об адаптации и не начнут добросовестно выполнять этот документ». Россия все еще надеется на возрождение адаптированного ДОВСЕ. 1 декабря 2009 г. во время выступления на заседании СМИД ОБСЕ в Афинах С.В. Лавров отметил: «Мы сожалеем, что последние два года оказались фактически потерянными для поиска выхода из кризиса. До сих пор нет ответа на наши предложения от 5 мая этого года о дальнейших шагах на основе российско-американского проекта «пакетного решения». Еще раз призываем партнеров перейти к интенсивной работе по восстановлению жизнеспособности ДОВСЕ с использованием всех каналов, включая Совместную консультативную группу в Вене» ${ }^{15}$.

Несмотря на очевидное превосходство по всем параметрам обычных вооружений (см. табл.), накануне введения Российской Федерацией моратория на исполнение ДОВСЕ, в заявлении от 7 декабря 2007 года, опубликованном после заседания Североатлантического Совета, министры иностранных дел Альянса признали, что «партнерские отношения между НАТО и Россией вышли на сложный этап» ${ }^{16}$. В ноябре 2011 г. США и Великобритания прекратили предоставлять России информацию согласно ДОВСЕ ${ }^{17}$.

15 Выступление Министра иностранных дел России С.В.Лаврова на 17-м заседании Совета министров ОБСЕ, Афины, 1 декабря 2009 года // Министерство иностранных дел Российской Федерации [сайт]. URL: http://www.mid.ru/ brp_4.nsf/0/68CF52D6D18132E1C325767F00571A30

16 Встреча Министров иностранных дел стран НАТО и России // Новости НАТО. - 2007.-№ 2. С. 3

17 Британия прекратит обмен военной информацией с РФ в рамках ДОВСЕ // Рамблер. Новости [сайт], 25 ноября 2011. URL: http://news.rambler.ru/11931627/; Дмитрий Медведев
Таблица.

Соотношение ВС в Европе ${ }^{18}$.

\begin{tabular}{|l|c|c|c|c|c|c|}
\hline $\begin{array}{c}\text { Основные } \\
\text { виды } \\
\text { боевой } \\
\text { техники }\end{array}$ & $\begin{array}{c}\text { НАТО } \\
\mathbf{1 9 9 0} \text { (тыс.) }\end{array}$ & $\begin{array}{c}\text { ОВД } \\
\text { (990 г. } \\
\text { (тыс.) }\end{array}$ & $\begin{array}{c}\text { дО- } \\
\text { ВСЕ } \\
\text { (тыс.) }\end{array}$ & $\begin{array}{c}\text { НАТО } \\
\text { 2007 г. } \\
\text { (тыс.) }\end{array}$ & $\begin{array}{c}\text { Рос- } \\
\text { сия } \\
\mathbf{2 0 0 7} \text { г. } \\
\text { (тыс.) }\end{array}$ & $\begin{array}{c}\text { Преиму- } \\
\text { щество } \\
\text { НАТО } \\
\text { (в раз) }\end{array}$ \\
\hline Танки & 38 & 45 & 20 & 23 & 8,3 & 2,8 \\
\hline ББМ & 85 & 110 & 30 & 38 & 15,4 & 2,5 \\
\hline $\begin{array}{l}\text { Артилле- } \\
\text { рия }\end{array}$ & 29 & 36 & 20 & 29 & 12,1 & 2,4 \\
\hline $\begin{array}{l}\text { Уд. верто- } \\
\text { леты }\end{array}$ & 4 & 5 & 2 & 3,1 & 1,5 & 2,0 \\
\hline $\begin{array}{l}\text { Б. само- } \\
\text { леты }\end{array}$ & 8 & 11 & 68 & 11,5 & 3,4 & 3,4 \\
\hline
\end{tabular}

По мнению специалистов Международного института стратегических исследований (IISS), опубликованном в авторитетном международном докладе «Военный баланс - 2008», решение России о выходе из ДОВСЕ является «ключевым событием в военной области» за 2007 год. Вкупе с произошедшим в декабре 2001 года выходом США из Договора по противоракетной обороне 1972 года и их дальнейшими планами по укреплению своей системы ПРО за счет развертывания ее элементов в Чехии и Польше, мораторий России продолжил «...серию шагов по разрушению инфраструктуры европейского контроля за вооружениями» ${ }^{19}$. Тем самым западные эксперты косвенно признали тот факт, что вопросы размещения обычных вооружений и систем противоракетной обороны на европейском пространстве безопасности тесно взаимосвязаны, а значит, попытки любой из сторон достичь преимущества могут привести к эскалации напряженности в регионе.

Адаптация ДОВСЕ - это вопрос, затрагивающий жизненные интересы России, наряду с вопросом расширения НАТО, системы американской ПРО и др. К сожалению, в этих вопросах США часто отказываются от равноправного диалога с Россией. Их позиция часто идет вразрез с положениями Основополагающего акта 1997 г. и Римской декларации 2002 г. и носит провокационный характер.

Несмотря на многочисленные обещания лидеров НАТО не обеспечивать свою безопасность за счет интересов России и заверения о «равноправ-

дал американцам асимметричный ответ // Рамблер. Новости [сайт], 23 ноября 2011. URL: http://news.rambler.ru/11889916/

18 Баранец В., Баранов А., Зибров В. Россия ответила на угрозу НАТО // Комсомольская правда. - 2007. - 16 июля

19 Смотров А. Выход России из ДОВСЕ разрушает режим доверия в Европе - эксперты. РИА Новости: URL: http:// www.rian.ru/world/20080205/98457774.html 


\section{Международные отношения / International Relations / № 1 / 2015}

ном партнерстве», в действиях блока прослеживается целенаправленная линия по наращиванию стратегического, тактического и оперативного перевеса в военной области, а также стремление оказывать политическое давление на Российскую Федерацию. Но последовательная политика Москвы последних лет по отстаиванию национальных интересов, ее решительные действия по пресечению грузинской агрессии, твердая позицию по статусу Абхазии, Южной Осетии и Крыма явно продемонстрировали, что создание эффективной европейской системы безопасности (центром ка- ковой себя полагает НАТО) невозможно без или против России.

Окончание «украинского кризиса», вероятно, возобновит сотрудничество между Россией и НАТО по многим направлениям. Но по нашему убеждению, взаимодействие сторон должно быть качественно иным, и, по всей вероятности, если исключить перспективу полноправного членства России в НАТО, осуществляться лишь на равноправной основе и в рамках международного права на основе юридически закрепленных межгосударственных договоренностей.

\section{Библиография:}

1. Арешев А.Г. ДОВСЕ. Устаревший договор и новые реалии // Международная жизнь. - 2007. - № 12.

2. Баранец В., Баранов А., Зибров В. Россия ответила на угрозу НАТО // Комсомольская правда. - 2007. - 16 июля.

3. Британия прекратит обмен военной информацией с РФ в рамках ДОВСЕ // Рамблер. Новости [сайт], 25 ноября 2011. URL: http://news.rambler.ru/11931627/

4. Встреча Министров иностранных дел стран НАТО и России // Новости НАТО. - 2007.-№ 2.

5. Выступление Министра иностранных дел России С.В.Лаврова на 17-м заседании Совета министров ОБСЕ, Афины, 1 декабря 2009 года // Министерство иностранных дел Российской Федерации [сайт]. URL: http://www.mid. ru/brp_4.nsf/0/68CF52D6D18132E1C325767F00571A30

6. Дмитрий Медведев дал американцам асимметричный ответ // Рамблер. Новости [сайт], 23 ноября 2011. URL: http://news.rambler.ru/11889916/

7. Договор об обычных вооруженных силах в Европе. Париж, 19 ноября 1990 года

8. Евсеев В. Обычные вооружения: Россия и Запад в зеркале ДОВСЕ // ВЕДОМОСТИ. - 2007. - 12 дек. - № 235 (2009).

9. Кулагин В.М. Международная безопасность: учебное пособие для студентов вузов. - М.: Аспект Пресс, 2007.

10. Противоречия России и НАТО //inoСМИ [сайт].-2014г.-07 янв.:URL: http://inosmi.ru/world/20140107/216322215. html

11. Смотров А. Выход России из ДОВСЕ разрушает режим доверия в Европе - эксперты. PИA Hoвости: URL: http:// www.rian.ru/world/20080205/98457774.html

12. Уткин А.И. Американская империя. - М,: Эксмо, 2003.

13. http://asozd.duma.gov.ru

14. Манойло А.В. Национально-государственные модели психологического управления конфликтами. // Обозреватель-Observer.-2008.-№2. - С.118-123

15. А. Э. Галумов Перспективы публичной дипломатии и имиджа ЕС в России // Международные отношения. - 2012. 1. - С. $118-127$.

16. Карякин В.В. Цивилизационная антропология американского экспансионизма: от доктрины Монро к глобальному лидерству // Международные отношения. - 2013. - 4. - C. 487 - 468. DOI: 10.7256/2305-560X.2013.4.9722.

17. Карпович О.Г. Международные организации и их роль в предупреждении, урегулировании и разрешении этнополитических конфликтов // Национальная безопасность / nota bene. - 2014. - 3. - С. 398 - 405. D0I: 10.7256/20738560.2014.3.11786.

18. Байректаревич A. Future of Europe (of Lisbon and generational interval) // NB: Международные отношения. - 2013. 4. - C. 16 - 26. DOI: 10.7256/2306-4226.2013.4.9399. URL: http://www.e-notabene.ru/wi/article_9399.html

\section{References (transliterated):}

1. Areshev A.G. DOVSE. Ustarevshii dogovor i novye realii // Mezhdunarodnaya zhizn'. - 2007. - № 12.

2. Baranets V., Baranov A., Zibrov V. Rossiya otvetila na ugrozu NATO // Komsomol'skaya pravda. - 2007. - 16 iyulya.

3. Britaniya prekratit obmen voennoi informatsiei s RF v ramkakh DOVSE // Rambler. Novosti [sait], 25 noyabrya 2011. URL: http://news.rambler.ru/11931627/

4. Vstrecha Ministrov inostrannykh del stran NATO i Rossii // Novosti NATO. - 2007.-№ 2.

5. Vystuplenie Ministra inostrannykh del Rossii S.V.Lavrova na 17-m zasedanii Soveta ministrov OBSE, Afiny, 1 dekabrya 2009 goda // Ministerstvo inostrannykh del Rossiiskoi Federatsii [sait]. URL: http://www.mid.ru/brp_4.nsf/0/68CF52D 6D18132E1C325767F00571A30

6. Dmitrii Medvedev dal amerikantsam asimmetrichnyi otvet // Rambler. Novosti [sait], 23 noyabrya 2011. URL: http:// news.rambler.ru/11889916/

7. Dogovor ob obychnykh vooruzhennykh silakh v Evrope. Parizh, 19 noyabrya 1990 goda.

8. Evseev V. Obychnye vooruzheniya: Rossiya i Zapad v zerkale DOVSE // VEDOMOSTI. - 2007. - 12 dek. - № 235 (2009). 
9. Kulagin V.M. Mezhdunarodnaya bezopasnost': uchebnoe posobie dlya studentov vuzov. - M.: Aspekt Press, 2007.

10. Protivorechiya Rossii i NATO // inoSMI [sait]. - 2014 g. - 07 yanv.: URL: http://inosmi.ru/world/20140107/216322215. html

11. Smotrov A. Vykhod Rossii iz DOVSE razrushaet rezhim doveriya v Evrope - eksperty. RIA Novosti: URL: http://www.rian. ru/world/20080205/98457774.html

12. Utkin A.I. Amerikanskaya imperiya. - M,: Eksmo, 2003

13. http://asozd.duma.gov.ru

14. Manoilo A.V. Natsional'no-gosudarstvennye modeli psikhologicheskogo upravleniya konfliktami. // Obozrevatel'Observer.-2008.-№2. - S.118-123

15. A. E. Galumov Perspektivy publichnoi diplomatii i imidzha ES v Rossii // Mezhdunarodnye otnosheniya. - 2012. - 1. C. $118-127$.

16. Karyakin V.V. Tsivilizatsionnaya antropologiya amerikanskogo ekspansionizma: ot doktriny Monro k global'nomu liderstvu // Mezhdunarodnye otnosheniya. - 2013. - 4. - C. 487 - 468. DOI: 10.7256/2305-560X.2013.4.9722.

17. Karpovich O.G. Mezhdunarodnye organizatsii i ikh rol' v preduprezhdenii, uregulirovanii i razreshenii etnopoliticheskikh konfliktov // Natsional'naya bezopasnost' / nota bene. - 2014 - 3. - C. 398 - 405. DOI: 10.7256/2073-8560.2014.3.11786.

18. Bairektarevich A. Future of Europe (of Lisbon and generational interval) // NB: Mezhdunarodnye otnosheniya. - 2013. 4. - C. 16 - 26. DOI: 10.7256/2306-4226.2013.4.9399. URL: http://www.e-notabene.ru/wi/article_9399.html 